\title{
BIỆN PHÁP NÂNG CAO CHẤT LỰ̛̣G KIỂM TRA ĐÁNH GIÁ KẾT QUẢ HỌC TẬP CỦA SINH VIÊN TRƯỜNG ĐẠI HỌC THỦ DÂU MỘT
}

\author{
Nhâm Văn Sơn ${ }^{(*)}$ \\ (*) Thạc sĩ. Truờng Đại học Thủ Dầu Một. Email: sonnv@tdmu.edu.vn
}

DOI: $\underline{10.37550 / \mathrm{tdmu} . \mathrm{CFR} / 2021.01 .141}$

\section{Tóm tắt}

Kiểm tra đánh giá là khâu then chốt cuối cùng của qúa trình dạy học. Đây cũng là khâu quan trọng tác động lón đến quá trình nâng cao chất luọng đào tạo. Việc kiểm tra đánh giá khách quan, nghiêm túc, đúng cách, đúng hướng sẽ là động lực mạnh mẽ khích lệ sự vuơn lên trong học tập của sinh viên, thúc đẩy sụ tìm tòi sáng tạo không ngùng của sinh viên. Nội dung bài viết này đề cập thục trạng hệ thống đánh giá kết quả ở Truờng Đại học Thủ Dầu Một, qua đó đề xuất biện pháp nâng cao chất luợng kiểm tra, đánh giá kết quả học tập của sinh viên.

Tù khóa: kiểm tra; đánh giá; kết quả học tập; chất luợng

\section{1. Đặt vấn đề}

Khả năng cạnh tranh của nguồn nhân lực phụ thuộc rất nhiều vào quá trình đào tạo của hệ thống giáo dục Đại học và Cao đẳng từng nước, ngoài những năng lực nhận thức cơ bản về chuyên môn, phải rèn luyện cho sinh viên những kĩ năng sống, làm việc trong môi trường thực tế, luôn thay đổi và nhiều thử thách. Trong quá trình đào tạo, việc kiểm tra đánh giá kết quả học tập - một khâu trọng yếu chỉ được tiến hành bằng những hình thức truyền thống như các câu hỏi trắc nghiệm khách quan hoặc trắc nghiệm tự luận, chỉ đòi hỏi sinh viên miêu tả lại những sự kiện riêng rẽ, hiếm khi yêu cầu sinh viên vận dụng những kiến thức đã học vào một tình huống thực trong cuộc sống.

Trường Đại học phải giúp sinh viên phát triển những kĩ năng, năng lực gắn liền với thực tiễn cuộc sống để sinh viên tốt nghiệp phải trình diễn được những năng lực thực tế, không phải chỉ bằng giấy bút như hiện nay. Thực tế cũng cho thấy, một bộ phận lớn sinh viên đã tốt nghiệp vẫn chưa được xã hội chấp nhận do không đủ năng lực để phục vụ được các nhiệm vụ thực tế, mà sự bất cập trong hệ thống đánh giá kết quả học tập là một vấn đề rất đáng quan tâm.

Đánh giá quá trình học tập phải được thể hiện thông qua bảng điểm của sinh viên và hệ thống chuẩn mực dùng để xác định các điểm số đó. Một nền giáo dục tiến bộ cần phải có một hệ thống điểm số đánh giá được chuẩn hoá, sao cho vừa có thể chuyển tải được hết 
mục đích của giáo dục, vừa giúp xã hội đánh giá chính xác mức độ có ích năng lực của sinh viên, đồng thời có thể giúp người học định hướng được mục tiêu và điều chỉnh được hành vi, để tự nâng cao kết quả học tập của bản thân.

Điểm số tự thân nó cao hay thấp không phải là một vấn đề, mà vấn đề ở chỗ chất lượng của hệ thống xác định nó. Chất lượng càng cao mức độ chuẩn hoá càng lớn, khả năng quốc tế hoá nền giáo dục đó càng cao. Trước yêu cầu hội nhập, việc nâng cao chất lượng kiểm tra đánh giá và hoàn thiện một hệ thống đánh giá kết quả học tập chất lượng cao là một yêu cầu tất yếu. Đối với các trường Đại học và Cao Đẳng vấn đề này lại càng có tầm quan trọng đặc biệt hơn.

\section{Nội dung}

\subsection{Thực trạng hệ thống đánh giá kết quả học tập ở trường Đại học Thủ Dầu Một hiện nay}

Bắt đầu từ năm học 2018 - 2019, kết quả học tập của các môn học được đánh giá theo thang điểm 10 với các điểm bộ phận: 1) 50\% đánh giá quá trình; 2) $50 \%$ đánh giá kết quả thi kết thúc học phần.

\section{Đánh giá tính chuyên cần của sinh viên}

Để đánh giá tính chuyên cần của sinh viên, giảng viên dựa vào: 1) Số buổi tham gia lớp học của sinh viên; 2) Tinh thần tham gia của sinh viên trong các tiết học và các giờ thảo luận.

Sinh viên tham gia lớp học là cần thiết để nghe giảng viên hướng dẫn những nội dung cơ bản của môn học. Trên cơ sở đó, sinh viên tự nghiên cứu và trình bày ý kiến trong buổi thảo luận. Vì vậy, việc đánh giá tính chuyên là thước đo mức độ sinh viên nắm được những nội dung cơ bản của môn học.

\section{Đánh giá kết quả kiểm tra giữa học phần}

Hình thức kiểm tra giữa kì của giảng viên rất phong phú. Giảng viên có thể kiểm tra nhiều lần trong quá trình học với thời gian và hình thức thích hợp. Thời lượng cho bài kiểm tra giữa kì có thể cả tiết học hoặc ngắn hơn. Việc kiểm tra như vậy sẽ giúp giảng viên hiểu được trình độ học tập của sinh viên và giúp sinh viên tích cực hơn trong học tập.

Với nhiều môn học, giảng viên đánh giá kết quả giữa kì dựa trên trình bày của cá nhân và nhóm về từng vấn đề được phân công. Đối với môn học có cả lý thuyết và thực hành hay môn học thực hành, sinh viên được kiểm tra thực hành. Hình thức này đánh giá kĩ năng làm việc nhóm, tranh luận, trao đổi trong quá trình chuẩn bị và khả năng thuyết trình của sinh viên trước đám đông.

\section{Đánh giá kết quả thi kết thúc học phần}

Có nhiều hình thức đánh giá mà các giảng viên thường sử dụng để đánh giá kết quả thi cuối kì của sinh viên. Có 2 hình thức chính là các bài thi viết (trắc nghiệm khách quan, tự luận ở hai dạng được tham khảo tài liệu hoặc không) và thi vấn đáp. 
Về quy trình ra đề thi, sử dụng ngân hàng đề thi, nhận đề thi, coi thi, chấm bài thi, lưu giữ bài thi... Thì tuân theo quy định của nhà trường (Mới có dự thảo quy định về công tác thi, kiểm tra mới)

\section{Nhũng bất cập phát sinh}

Thực tế hiện nay, mặc dù phương pháp đánh giá đã có nhiều cải tiến tích cực nhưng vẫn còn nhiều vấn đề cần phải bàn để tiếp tục hoàn thiện :

- Hình thức thi và kiểm tra: Chủ yếu vẫn là thi và kiểm tra viết.

- Phạm vi thi và kiểm tra: Vẫn còn tình trạng một số môn học giới hạn phạm vi quá hẹp trên một diện rất rộng kiến thức sinh viên được học, do đó dẫn tới tình trạng sinh viên học tủ, học lệch, học đối phó.

- Nội dung thi và kiểm tra: Các câu hỏi thi và kiểm tra còn nhiều trùng lắp, thiếu tính sáng tạo. Nhiều câu hỏi chủ yếu là tái hiện kiến thức lý thuyết, thậm chí ra đúng như đề mục trong bài, vì vậy nhiều sinh viên bỏ tiết không đi học nhưng vẫn thi được là nhờ học thuộc lòng (học vẹt, không cần hiểu) hoặc quay cóp.

- Ngoài ra vẫn còn có tình trạng: Giáo viên, khoa, bộ môn (mặc dù rất cá biệt) do chạy theo thành tích nên dẫn tới tâm lý dễ dãi trong việc đánh giá kết quả học tập của sinh viên, ảnh hưởng đến tính động viên thi đua trong sinh viên và giữa các khoa bộ môn.

- Tùy tiện trong cách đánh giá kết quả học tập. Kết quả là hệ thống điểm số đánh giá khác nhau không chỉ xảy ra ở cấp trường, cấp khoa, bộ môn, mà cả giữa các giáo viên trong từng bộ môn. Trên bình diện xã hội nhiều trường có tên tuổi, có điểm số tuyển sinh đầu vào cao nhưng lại có điểm số bình quân khá thấp, số sinh viên bị buộc thôi học hàng năm chiếm tỷ lệ khá lớn, trong khi tình hình lại xảy ra ngược lại ở các trường mới hình thành.

- Phương pháp đánh giá sinh viên chưa thực sự động viên sinh viên phấn đấu vươn lên trong học tập. Việc đánh giá sinh viên của mỗi giảng viên chưa thực sự đồng nhất, còn nhiều sai biệt khác nhau, có môn thì quá chặt, có môn thì quá nới lỏng.

\subsection{Biện pháp nâng cao chất luợng kiểm tra đánh giá kết quả học tập}

Tại hội nghị của Hội Tâm lý học Mỹ năm 1948, B. S. Bloom đã chủ trì xây dựng một hệ thống phân loại các mục tiêu của quá trình giáo dục. Ba lĩnh vực của các hoạt động giáo dục đã được xác định, đó là lĩnh vực về nhận thức, kỹ năng và thái độ.

Lĩnh vực nhận thức thể hiện ở khả năng tư duy, suy nghĩ, lập luận,suy luận.. bao gồm việc thu thập các sự kiện, giải thích, lập luận theo kiểu diễn dịch và quy nạp và sự đánh giá có phê phán.

Lĩnh vực kỹ năng đòi hỏi sự khéo léo về chân tay, sự phối hợp các cơ bắp từ đơn giản đến phức tạp và mối quan hệ giữa các quá trình tâm lý và quá trình vận động thực hiện các thao, động tác.

Lĩnh vực cảm xúc liên quan đến những đáp ứng về mặt tình cảm, cảm xúc bao hàm cả những mối quan hệ như yêu ghét, thái độ nhiệt tình thờ ơ, quan tâm..cũng như sự cam kết với một nguyên tắc và sự tiếp thu các lý tưởng. 
Các lĩnh vực nêu trên không hoàn toàn tách biệt hoặc loại trừ lẫn nhau mà gắn kết, hỗ trợ nhau hình thành phẩm chất và năng lực của mỗi cá nhân.

Sự thể hiện của các cấp độ cho ở bảng 1 :

Bảng 1. Các mức độ nắm vũ̃ng kiến thức

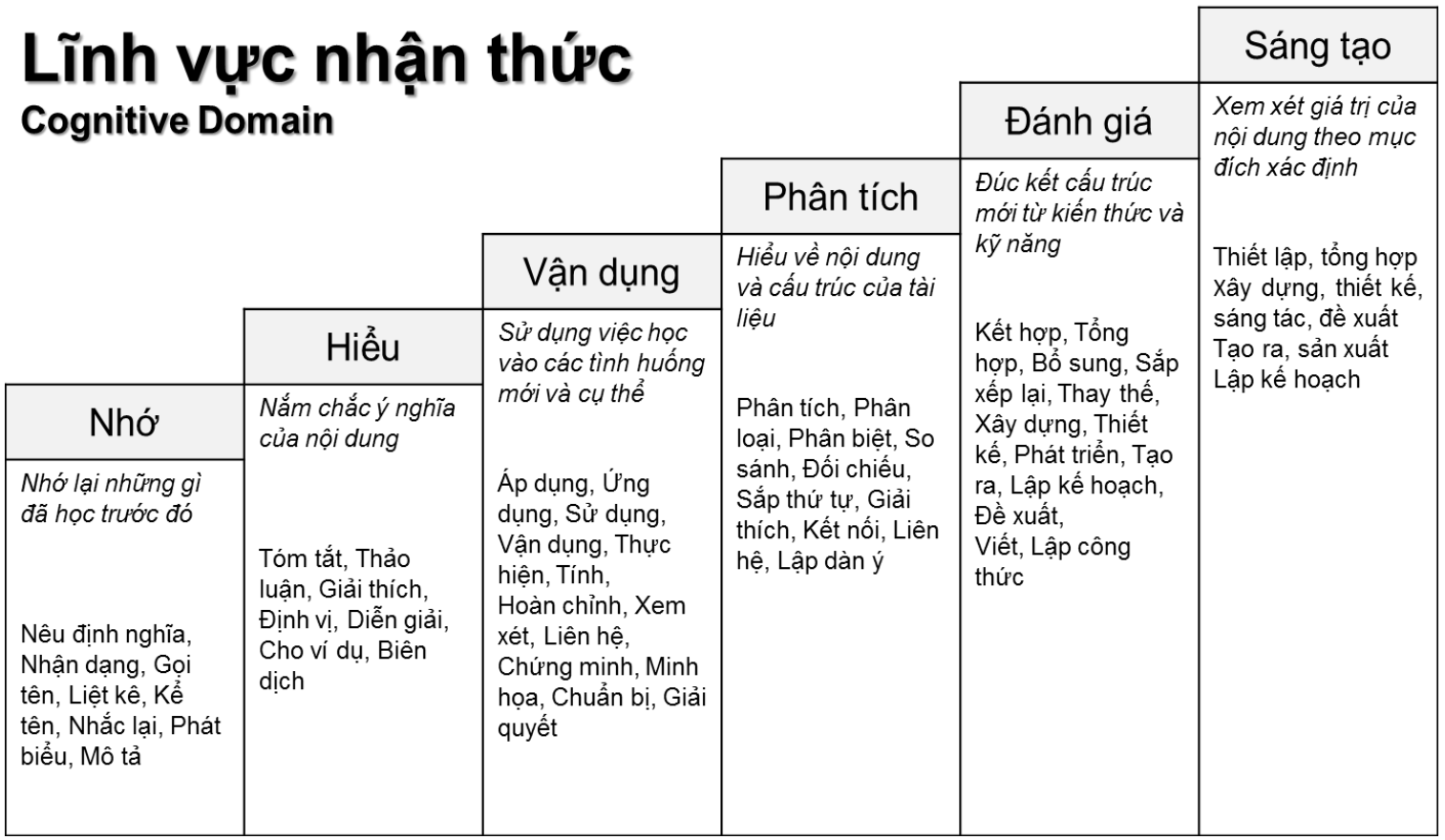

Bảng 2. Các mức độ hình thành kỹ năng

\section{Lĩnh vụ̂c kỹ năng Psychomotor Domain}

\begin{tabular}{|c|c|c|c|c|c|c|}
\hline & \multirow{7}{*}{$\begin{array}{l}\text { Vận dunng các } \\
\text { kỹ năng trong } \\
\text { các tình huống } \\
\text { có vấn đề } \\
\text { Vận dụng, } \\
\text { Nhận ra, Thay } \\
\text { đổi, Xem xét lại }\end{array}$} & \multirow{2}{*}{$\begin{array}{l}\text { hành động cụ } \\
\text { thể }\end{array}$} \\
\hline & & & & Phản ứng lại & & \\
\hline & & & Kỹ xảo & $\begin{array}{l}\text { Thực hiên một } \\
\text { cách tự động }\end{array}$ & & \multirow{5}{*}{$\begin{array}{l}\text { Thiết kế, Sáng } \\
\text { chế, Kết hợp, } \\
\text { Sáng tác/soạn, } \\
\text { Xây dựng }\end{array}$} \\
\hline & & $\begin{array}{l}\text { Phản hồi có } \\
\text { hướng dẫn }\end{array}$ & \multirow[t]{2}{*}{$\begin{array}{l}\text { Thể hiện hành } \\
\text { động với hiệu } \\
\text { quả cao hơn }\end{array}$} & & & \\
\hline & Ôn định & \multirow{2}{*}{$\begin{array}{l}\text { Bắt chước và } \\
\text { luyện tập các kỹ } \\
\text { năng, thường là } \\
\text { theo từng bước }\end{array}$} & & $\begin{array}{l}\text { Điều khiển, } \\
\text { Hướng dẫn, Chỉ }\end{array}$ & & \\
\hline Nhận thức & \multirow{2}{*}{$\begin{array}{l}\text { Sã̃n sàng về } \\
\text { mặt tinh thần, } \\
\text { cảm xúc và thể } \\
\text { chất để hành } \\
\text { động } \\
\text { Ngồi, Đứng }\end{array}$} & & \multirow{2}{*}{$\begin{array}{l}\text { Tạo ra, Thực } \\
\text { hiện, Biễu diễn, } \\
\text { Làm ra, Sản } \\
\text { xuất }\end{array}$} & $\begin{array}{l}\text { dẫn, Quản lý, } \\
\text { Tổ chức }\end{array}$ & & \\
\hline $\begin{array}{l}\text { Các giác quan } \\
\text { định hướng các } \\
\text { hoạt động } \\
\text { Nghe, Lắng } \\
\text { nghe, Quan sát, } \\
\text { Nhận thấy, } \\
\text { Nhận ra }\end{array}$ & & $\begin{array}{l}\text { Chép lại, Bắt } \\
\text { chước, Luyện } \\
\text { tập, Lặp lại }\end{array}$ & & & & \\
\hline
\end{tabular}

Bảng 3. Các mức độ của lĩnh vực thái độ 


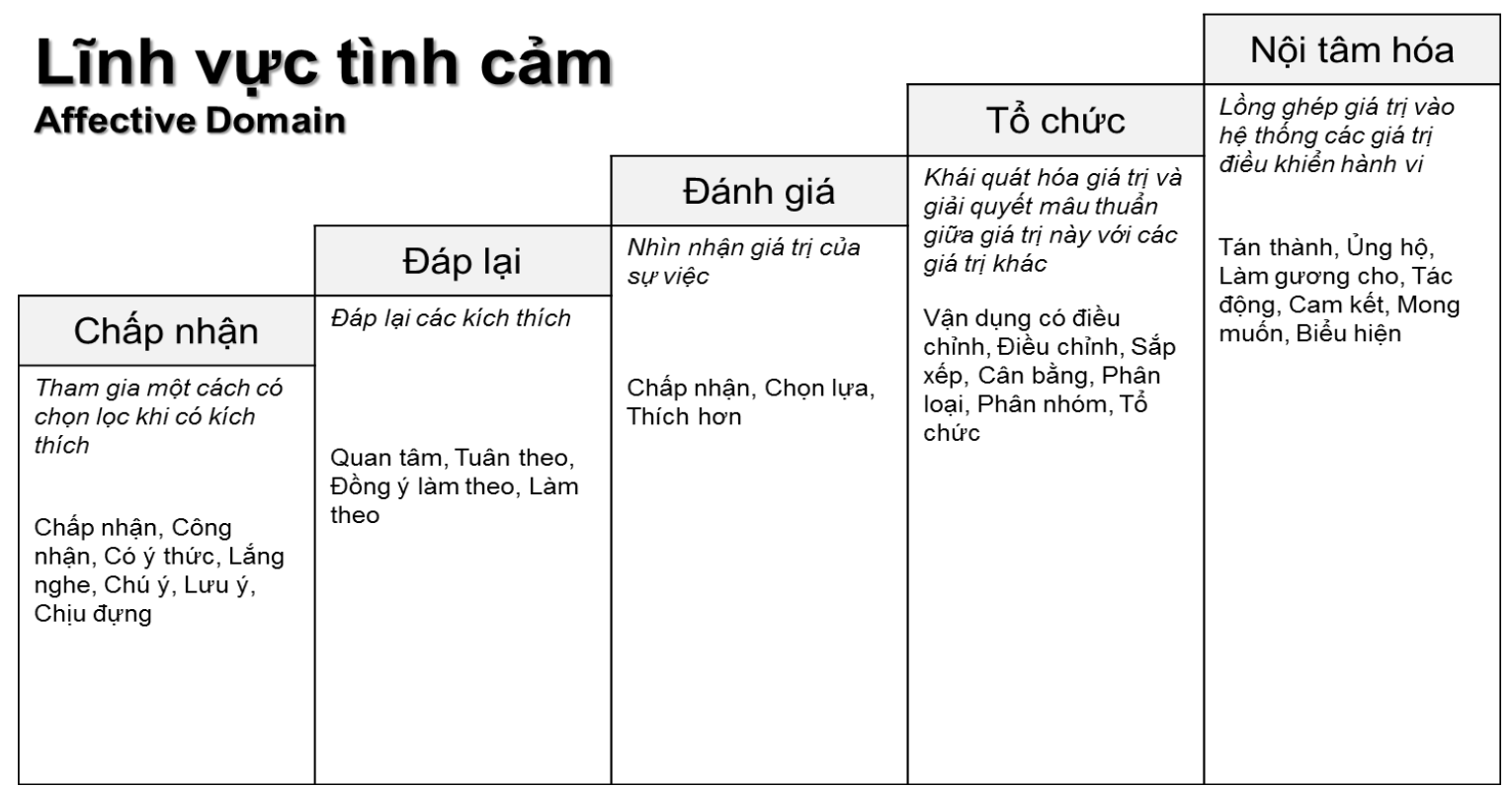

Hiện nay phương pháp đánh giá truyền thống vẫn có những ưu điểm của nó (có thể đánh giá hiệu quả của quá trình nhận thức của sinh viên, và cũng có thể tái nhận hay tái hiện một vấn đề gì đó trong cuộc sống thực. Ví dụ, mục tiêu của bài học chỉ là nắm vững kiến thức nào đó, thì một vài câu hỏi nhiều lựa chọn hoặc câu trả lời ngắn có thể đánh giá được mức độ đạt mục tiêu này do đó cần tiếp tục duy trì. Trong mô hình đánh giá truyền thống, sinh viên ít có cơ hội để trình diễn những gì họ học được bằng nhiều cách khác nhau. Tuy nhiên, đề thi được thiết kế tốt cho phép xác định vị trí của từng sinh viên so với những sinh viên khác trong cùng một lĩnh vực.Trong quá trình thực hiện tôi thấy cần chú ý các biện pháp sau:

- Áp dụng nhiều hình thức thi kiểm tra một cách linh hoạt phù hợp, như : thi viết, thi vấn đáp, thi trắc nghiệm... Mỗi hình thức có những ưu nhược điểm riêng. Tuỳ vào đặc trưng môn học, khối lượng kiến thức, đặc trưng nghề nghiệp tương lai của sinh viên, mà chúng ta có sự lựa chọn, phối hợp vận dụng linh hoạt các hình thức phù hợp nhằm đạt được hiệu quả cao và công bằng.

- Nếu giảng viên trong quá trình dạy học chỉ tập trung chủ yếu vào những kiến thức sẽ được thi thì kết quả điểm thi không phản ánh đúng năng lực của sinh viên về học phần đó.

- Nội dung thi phải đảm bảo toàn diện, gắn lý luận với thực tiễn, tránh tình trạng tái hiện đơn thuần lý thuyết và thiếu tính vận dụng sáng tạo, nhằm hướng đến mục đích vừa kiểm tra được trên diện rộng những kiến thức cơ bản mà sinh viên cần nắm, vừa tạo điều kiện cho người học được rèn luyện kỹ năng nghiệp vụ và được bộc lộ các khả năng tư duy phong phú của mình.

- Tuỳ từng môn học, có thể áp dụng kết cấu đánh giá: Bao nhiêu \% cho đánh giá giữa kì, bao nhiêu \% cho đánh giá kết thúc môn học... cho phù hợp nhằm đảm bảo tính chính xác, tính toàn diện và tính động viên thi đua. 
- Tránh tình trạng chạy theo thành tích mà "vượt rào" các quy chế, nội quy thi và kiểm tra, làm ảnh hưởng đến sản phẩm đào tạo, ảnh hưởng đến thương hiệu mà Trường đang cố gắng tạo dựng.

- Hệ thống điểm số đánh giá khác nhau (không chỉ xảy ra ở cấp trường, cấp khoa, bộ môn, mà cả giữa các giáo viên trong từng bộ môn) là do chúng ta chưa xây dựng được “Chuẩn” (Mặc dù đã có chuẩn đầu ra được xây dựng theo đề cương chi tiết)

Đối với bất kỳ hình thức đánh giá nào việc đầu tiên quan trọng nhất là phải xác định chúng ta định kết thúc ở đâu, sinh viên phải làm gì sau một giai đoạn học tập. Một bài đánh giá không thể cung cấp những thông tin có giá trị nếu nó không đo được cái định đo. Do vậy, nếu không xác định được rõ ràng mục đích, mục tiêu của việc học tập thì mọi bước tiếp theo đều vô ích.

Chuẩn chính là lời tuyên bố về điều sinh viên cần biết và có thể làm được. Tuy nhiên, so với mục đích, chuẩn có phạm vi hẹp hơn, dễ thay đổi hơn trong cách đánh giá

Sứ mạng ( Chuẩn đầu ra ) là tuyên bố rộng và chung nhất của một trường Đại học về những gì sinh viên của họ cần biết và có thể làm được khi ra trường. Sứ mạng được công bố cho toàn thể xã hội biết về tôn chỉ, mục đích giáo dục của nhà trường đó.

Mục đích hẹp hơn sứ mạng song vẫn đủ rộng cho một bài học hay cấp học, xác định những kỳ vọng chung đối với sinh viên ở cấp học đó. Sú mạng và mục đích thường chỉ cung cấp những kỳ vọng mang tính định hướng, không đo lường đánh giá và quan sát được.

Mục đích được chia nhỏ hơn thành các chuẩn. Nếu mục đích là những kỳ vọng chung cho một cấp học thì chuẩn có xu hướng cụ thể hoá cho một lớp học ứng với một đơn vị nội dung (1-2 chương) và một đơn vị thời gian (2-3 tuần).

“Chuẩn” phải có tính bao quát cao trên nhiều mặt, phản ánh chính xác năng lực của sinh viên, phù hợp với các chuẩn mực khoa học theo từng học phần, thống nhất giữa các trường ở trong nước. Trên cơ sở đó tuỳ theo yêu cầu của mỗi giai đoạn và đặc thù riêng có, mỗi Trường có thể được gia giảm thêm một biên độ hợp lý.

Đánh giá thưc là gì: Đánh giá thực là một hình thức đánh giá trong đó người học được yêu cầu thực hiện những nhiệm vụ thực sự diễn ra trong cuộc sống, đòi hỏi phải vận dụng một cách có ý nghĩa những kiến thức, kĩ năng thiết yếu

Đặc trưng của đánh giá thực là:

Yêu cầu sinh viên phải kiến tạo một sản phẩm chứ không phải chọn hay viết ra một câu trả lời đúng.

Đo lường cả quá trình và cả sản phẩm của quá trình đó.

Trình bày một vấn đề thực - trong thế giới thực cho phép sinh viên bộc lộ khả năng vận dụng kiến thức vào tình huống thực tế.

Cho phép sinh viên bộc lộ quá trình học tập và tư duy của họ thông qua việc thực hiện bài thi.

Ủu việt của đánh giá thực: 
- Đánh giá thực yêu cầu sinh viên thể hiện sự hiểu biết thông qua việc hoàn thành một nhiệm vụ

- Đánh giá thực yêu cầu sinh viên trình diễn năng lực của họ trong một công việc cụ thể.

- Đánh giá thực thường yêu cầu sinh viên phải phân tích, tổng hợp một cách có phê phán những kiến thức họ học được trong bối cảnh thực và trong quá trình đó họ sáng tạo ra ý tưởng mới.

Đánh giá truyền thống và đánh giá thực không loại trừ nhau, mà ngược lại, bổ sung cho nhau nhằm đánh giá một cách toàn diện và chính xác nhất việc đạt mục tiêu của chương trình khoá học, môn học hay bài học. Mục tiêu của chương trình khoá học, môn học hay bài học có thể ở nhiều lĩnh vực khác nhau (nhận thức, tình cảm, kĩ năng, năng lực v.v.) và cũng không phải mục tiêu nào cũng yêu cầu sinh viên phải trình diễn năng lực vận dụng kiến thức hay kĩ năng.

\section{Kết luận}

Trong nhà Trường, chúng ta chỉ quan tâm đến lượng kiến thức mà sinh viên thu nhận được chứ ít khi đánh giá được họ sẽ sử dụng những kiến thức đó trong cuộc sống ra sao. Do vậy một bài thi chỉ có ý nghĩa khi nó yêu cầu sinh viên thực hiện một nhiệm vụ thực.

Đánh giá truyền thống dùng để đánh giá sự tiếp nhận kiến thức, kỹ năng của sinh viên và thường được xây dựng từ những câu hỏi nhiều lựa chọn và một số câu tự luận kiến tạo. Ngược lại, đánh giá thực bao gồm những nhiệm vụ như trình diễn, sản phẩm và cả những câu hỏi kiến tạo đòi hỏi sinh viên có sự vận dụng trực tiếp kiến thức, kỹ năng vào đời sống thực.

Đánh giá thực không loại trừ đánh giá truyền thống mà chỉ là sự bổ sung hoàn hảo giúp người dạy cũng như người học gắn kết những kiến thức, kỹ năng được học trong trường với cuộc sống thực, giúp người học có ý thức hơn với những nhiệm vụ mà họ sẽ phải thực hiện khi tốt nghiệp. Quá trình dạy học trong trường cũng nhờ đó mà trở nên sống động hơn, giảng viên sẽ tìm tòi, sáng tạo hơn để tìm ra các bài tập hay, hỗ trợ sinh viên thực hiện các nhiệm vụ đó. Sinh viên sẽ khát khao hơn trong quá trình tiếp nhận tri thức, rèn luyện kỹ năng để làm một việc có ý nghĩa hơn ngay từ khi còn trên ghế nhà trường.

Để thực hiện được kiểu đánh giá thực trong phạm vi toàn trường, người lãnh đạo phải thể hiện quyết tâm chính trị của mình, hỗ trợ giảng viên, sinh viên thay đổi cách dạy, cách học, loại bỏ cách kiểm tra đánh giá theo những mục tiêu hạn hẹp, lạc hậu. Đổi mới kiểm tra đánh giá phải bắt đầu từ việc xác lập những mục tiêu học tập gắn chặt với đời sống thực, rồi từ đó phát triển đội ngũ, đổi mới chương trình, tài liệu học tập. Đây là công việc khó, phải tiến hành trong thời gian dài, tốn nhiều công sức, nhưng đã đến lúc phải bắt đầu!

Đối với đánh giá thục thì khái niệm chuẩn phù hợp hơn cả, bởi lẽ cũng như mục tiêu, chuẩn là những phát biểu có thể quan sát được, đánh giá được, là điều kiện thiết yếu để xây dựng nhiệm vụ thực. Hơn nữa, chuẩn có phạm vi bao quát một đơn vị nội dung lớn hơn bài học và có thời gian dài hơn, phù hợp hơn với việc thiết kế một bài đánh giá thực. Vì vậy cần phải xây dựng chuẩn. 
Nâng cao chất lượng giảng dạy nói chung là một vấn đề bức xúc. Tuy nhiên, không phải vì thế mà chúng ta phải tiến hành một cách vội vàng, mà phải coi đó là phương châm giáo dục, là chiến lược giáo dục cần kiên trì thực hiên lâu dài đồng bộ. Đặc biệt, nếu được các cấp lãnh đạo quan tâm đầu tư thích đáng, được cán bộ giáo viên nhận thức sâu sắc và hưởng ứng hợp tác thì chắc chắn sẽ thành công.

\section{Tài liệu tham khảo}

[1] Bộ Giáo dục và Đào tạo (2019), Tài liệu hội nghị triển khai chương trình giáo dục phổ thông mới, Hà Nội.

[2] Bộ giáo dục và đào tạo (2016), Thông tư Số: 04/2016/TT-BGDĐT - Ban hành Quy định về tiêu chuẩn đánh giá chất lượng chương trình đào tạo các trình độ của giáo dục đại học, Hà Nội, ngày 14 tháng 3 năm 2016.

[3] Đại học quốc gia TP.HCM (2016), Tài liệu hướng dẫn Tài liệu hướng dẫn đánh giá chất lượng cấp chương trình theo tiêu chuẩn AUN - QA (phiên bản 3.0), Nxb ĐHQG-HCM.

[4] https://tdmu.edu.vn/ 